\title{
Article
}

\section{Renewable energy policy around the globe}

\author{
Ahmed Mahmood ${ }^{1}$, Muhammad Qasim ${ }^{2}$ and Muhammad Faisal Khan ${ }^{3, *}$ \\ 1 Pak Datacom Limited, Lahore, Pakistan. \\ 2 Department of Electrical Engineering, University of Sialkot, Sialkot, Pakistan. \\ 3 Department of Electrical Engineering, Shanghai Jiao Tong University, Shanghai, China. \\ * Correspondence: khanfaisal@sjtu.edu.cn; muhammadfaisalkhan323@yahoo.com
}

Received: 1 January 2021; Accepted: 15 September 2021; Published: 30 September 2021.

\begin{abstract}
Renewable energy systems (RESs) have an inherent quality of achieving independence Vis a Vis useful energy harnessing for self or localized use. At larger scale the renewable energy system allows the power generation and distribution without a significant harm to the environment. Propagation and proliferation of RESs and the Renewable Energy Technology (RET), collectively demand an effective policy making infrastructure to be in place to ensure their penetration locally and globally. Renewable Energy Policies have a great impact on how readily these systems are adopted by the investors and market, how efficient these systems are which is dependent on the research and development (R\&D) of RESs, how effectively the country or region copes with the scourge of environmental harm with the use of RESs. Renewable Energy Policies also have an impact on how costly these technologies are and how these technologies fiscally benefit common man, investors and industries. Efficiency enhancement, stability and intelligent management of grids integrated with RES are also renewable policy dependent. This paper thoroughly and critically examines the importance of renewable energy policy. not just at domestic or national level but also at global level. It discusses in detail the core ingredients of renewable energy policy which were adopted in the past, which are being adopted now and which should be adopted in future. This paper also discusses policy, business and financial models; importance of tariff formulation, incentives and subsidies and a few factors which may pose a risk to the development and adoption of RESs. At the end a few suggestions have also been made which, if adopted, would help promote the RESs proliferation across the globe at a rapid pace and would ensure energy security, sustainable development and environmental conservation.
\end{abstract}

Keywords: Renewable energy system; Renewable energy technology; Greenhouse gases; Information and communication technology; Feed-in Tariff; Feed-in Premium; Renewable portfolio standard; Micro renewable energy systems; Renewable energy certificate; Tradable green credits; Demand response; Generation expansion planning.

\section{Introduction}

$\mathbf{E}$ nergy policy, in general, is the stipulation of standard procedures and regulations by governmental or global bodies to look after the issues related to energy generation, distribution and end-user consumption. The salient features of energy policy include local or global legislations, treaties, investment-incentives, regulations regarding conservation of energy, monetary tax regulations and other significant factors impacting public well-being and development. In the current era, energy acts as the pivot to all economic activities of a region in general and a country in particular as it is required by the industry, agriculture, communication and transportation sectors among several others.

With the development and implementation of modern renewable energy systems at global scale, the dimensions of energy policy have evolved into renewable energy policy. The renewable energy policies are not only being developed and implemented at state level through governments, but also at global level through international agencies, syndicates and think tanks like IRENA or the International Renewable Energy Agency, REN-21 or the Renewable Energy Policy Network for the 21st Century, REEEP or the Renewable Energy and Energy Efficiency Partnership, ISA or the International Solar Alliance, EREC or the European Renewable Energy Council and the Energy and Climate Partnership of the Americas (ECPA) to name a few. 
The renewable energy policies take into account deployment planning, legislation on commercial aspects of renewable energy systems along with their efficiency standards, fiscal policies, energy security and implementation of the above in accordance with international treaties, agreements and alliances. Another major issue being looked after in the global policy making is the effect of all these systems upon the climate, environment and ecology [1].

The major factors which are defined in the regional or global renewable energy policies include;

1. Present and future potential of self-sufficiency with regard to renewables,

2. How and where the renewable systems will be deployed,

3. Management of renewable energy distribution,

4. Environmental impact of the deployed renewable energy setups,

5. Encouragement of energy efficient hardware adoption,

6. Technology Modernization and reduction in Green House Gas (GHG) emissions,

7. Incentives and mechanisms to promote the use of renewables at regional and global scales [2].

Effective policies on renewable energy systems can give an impetus to innovation in manufacturing and cost reduction along with their adoption as a clean and cost-effective source of power generation. Different countries have adhered to different laws and renewable energy policies to promote the adoption of renewable energy technologies [3]. The significance of these policies usually varies from one country to the other and is primarily based on their geographical diversity, economic conditions, preferences and social trends.

Global policies to propagate renewable energy have played a key role in their expansion. Europe is regarded as the pioneer in defining renewable energy policy in early 2000s. Following the footsteps of Europe, now most countries around the world have formed such policies to cater for their plans to deploy and promote renewable energy systems. Major inter-governmental organizations are playing a key role for promoting the adoption of renewable energy worldwide. They have been providing policy advice and motivating member countries to develop and improve renewable energy policies apart from helping them with capacity building and technology transfer [4]. These organizations have also identified the fact that the renewable energy has the potential to take poor countries to a higher level of prosperity.

The global policy on renewable energy systems is also having a positive impact on evolution of next generation technologies. As the focus is now shifting from fossil fuels to renewables, several new technologies have been created as a result of more focused research and development in the renewables domain. These newly evolved technologies are not only proving to be cost-effective, but also offer an easier, effective and efficient way of their deployment regardless of where they are being deployed.

A close study of literature related to global renewable policy brings to light the fact that the momentum of fossil-fuel market and consumption still impedes the adoption of renewable energy systems owing to the geopolitical preferences of key global players. Some of the countries have even adhered to the policy of discouraging the proliferation of renewable energy systems not just within their own political boundaries, but also in their neighboring regions and trade-partners. Despite these impeding factors, effective policy-making vis-vis renewables is still on-going at national as well as global scale and is gradually gaining the pace to address all the issues related to the growth of renewables for sustainable development and complete reliance on green energy resources.

This paper will encompass all the key policies which are being introduced and implemented by inter-governmental organizations across the globe and will also highlight the policy preferences and structures being adopted by various countries across different regions regarding the development and promotion of renewable energy resources. It will also discuss which renewable policy is lopsided in the favour of which renewable technology by using the detailed data provided in the latest global renewable energy policy reports recently published in different research studies critically analyzing different governmental policy instruments.

\section{Literature Review}

Policies pertaining to renewable energy systems (RES) play an important role in their effective deployment and promotion for any country. Due to diminishing fossil fuel reserves, their inherent tendency of spreading the much talked about greenhouse gases (GHGs) and increasing prices, nearly all countries across the globe have formulated some type of policy regarding the promotion and deployment of renewables to counter these adverse factors. Policies of some developed countries or key players in the domain of RES are 
exemplary while for some, the policy formulation process either has some loopholes or is still in its nascent stages.

There are several publications regarding the comparative analyses of renewable energy policies which have highlighted the pros and cons of these policies either by directly discussing their quality or effectiveness in short-term, as well as long-term scenarios or by comparing the magnitude of their quality as compared to policies of other countries or those defined by inter-governmental organizations on renewables. Having studied the reports, journals and technical papers on global renewable energy policies, one can easily conclude that the policy formulation and their implementation are still not perfectly defined and are constantly evolving with several modifications and improvements with every passing year. Some of the countries which have achieved the technical excellence in manufacturing and deployment of renewable energy systems through dedicated research and development are in a position to take effective policy measures Vis a Vis their implementation and effectiveness. Some policies are unique to a particular country or region while some are common across the globe. These policy matters are significantly affected by social preferences, political tendencies and geo-political scenarios.

Most of the studies begin with discussing the current issues in the domain of renewable energy with reference to policies of the past and those which have been currently implemented. Then a solution in the form of a new business or technical model is suggested and a restructured policy is proposed. In [5], S. Han et al., have discussed the current trend of renewable energy policy in South Korea. They have discussed the contemporary issues associated with instability in the supply of power from renewable energy sources along with the low efficiency issues offered by such systems. By observing the national policy trends, they have tried to propose an effective business model which could be used to address afore mentioned issues. They have also identified that the development and implementation of renewable energy systems is not the only solution in this regard, rather there is a need to develop a compact and interactive power system integrated with state-of-the-art information and communications technology (ICT) based solutions and platforms. Another observation made in [5] is that efficient energy use could be achieved by deploying advanced energy storage systems (ESSs) with an intelligent and agile demand-side management systems such as the EMS or the energy management system also termed in the modern technological nomenclature as the demand response (DR) system.

In one study about electrification of Ethiopian Power Sector using renewables, Md Alam Hossain et al., [6] suggest the use of diversified energy supply-mix to achieve energy security and sustainable energy system development with zero carbon emission and increased export options. It also suggests the use of market allocation (MARKAL) energy system model of energy to achieve all these mentioned objectives. For diversification of renewable energy sources, a mixed use of frontline renewable energy technologies like Hydro, PV and wind have been suggested. The effectiveness of Market allocation scheme has also been discussed by Ricardo Fagiani et al., [7] wherein such a policy of the European Commission implemented to introduce competitive allocation mechanism has been discussed. This policy ensures that the market players reveal their actual generation cost which would further help the policy makers with effective price formulation. It also discusses the pros and cons of commission's recommendations regarding allocation of feed-in premiums (FiPs) through tender and quota obligation schemes. In [8], Song Yun-Wei has examined the renewable energy policy development in the USA. The policies regarding the green consumption and consumer protection have been discussed at stretch to verify their effectiveness. He concludes his study with the argument that renewables still suffer to compete with traditional energy due to the high cost of its implementation. He also states that the renewable technologies are still under development for their efficiency and reliability and that the public is still unaware of the benefits of deploying renewable energy harnessing techniques. Other obstacles that have been identified include the lack of research and development funds and the subsidies that still exist for the deployment of power generation systems using traditional non-renewable sources.

The single largest barrier in the non-adoption of renewable energy systems globally is policymaking as identified by Nathan Murthy et al., [9]. They propose that effective policy recommendations are needed to accelerate the penetration of renewables at national as well as global scale. Their study also states that a sustained policy support for demand dispatch in combination with integrated intermittent generation through renewables is important to achieve the goal of meaningful inclusion of renewables to the grid. It also been suggested that a National Action Plan be proposed to delineate a comprehensive climate strategy, incentives be introduced to promote renewables against the traditional fossil fuel-based generation systems, subsidies to 
fossil fuel-based producers be removed in favor of renewables and an effective Feed-in Tariff (FiT) policy be introduced. A study about the renewables policy in different States of the US has been presented by Olawale Ogunrinde et al., [10] . According to their report, several policies to incentivize the proliferation of RESs have been implemented in several states. One of these policies is the renewable portfolio standards (RPS) which ensures that renewable energy sources contribute to a certain percentage of the total electricity sales. It has been observed that the returns on RPS are location specific and RPS mandate implementation is still not fully functionalized due to lack in development of renewables integration technologies.

China's renewable policies and regulations have been discussed in [11] which suggests that China has a strong policy structure to achieve the sustainable development and to overcome the menace of climate change. According to this report China has implemented instruments from laws, policies and financial incentives. Chinese policymakers have clearly identified that renewable energy is without a doubt unavoidable for sustainable economic growth and development. They have been weaving their policies around the idea that it is imperative to have reduced production cost and technological reliability of renewable energy systems. To further the effectiveness of China's policies regarding renewables, authors suggest that legal and institutional frameworks along with a supportive policy must be brought forth. Security and sustainability of public sector, promoting the involvement of private sector, R\&D across all sectors, establishment of small and medium enterprises related to renewable energy systems and access to affordable finance have been identified as areas which must be taken into account for improvement in existing policies. Reforms are also needed create a positive investment climate so that the attention of private sector with its capital towards renewable energy could be attracted which will further expand international cooperation in this domain. Further policy suggestions in [12] include development of advanced and efficient renewable energy systems which could be achieved with the definition of specific energy development objectives, mandatory and effective legislation, administrative intervention and establishment of a complete research and design institution.

Shyam B. et al., in [13] discuss policies, opportunities and challenges related to renewable energy systems in India. India is one of the global leaders in the deployment of renewable energy systems and has implemented an effective policy mechanism to promote the deployment and utilization of renewables across the country. It is known to Indian policy makers that utilization of renewable energy is crucial to nation's energy security and economic stability. In India, the renewable energy sector is supported by the government with significant amount of financial, educational and institutional aids. Owing to India's effective and reliable renewable policies, strategies and frameworks, the country has witnessed prolific deployments of renewable energy harvesting systems widely dispersed across the country. The publication also discusses the potential challenges faced by the power sector in integrating the renewable energy systems with the existing grids and significance of smart-grid in this regard. It also highlights the work being done in the domain of smart-grid to overcome all the challenges related to renewable systems integration and energy management. Another important take-away from this discussion is the healthy environment created by the government to ensure the involvement of private sector, particularly in the domain of wind power. R\&D in the domains of micro-grids, storage systems and smart-grid is being emphasized. Authors in [14] introduce the generation expansion planning (GEP) method and policy and evaluate its effectiveness. The objective of GEP is to identify the most feasible combination of different conventional or fossil-fuel based energy sources in combination with RESs to overcome the power demand in a predictable manner. It involves a clearly defined algorithm for its implementation which monitors all the demand and available supply parameters for optimized decision making strictly including parameters from renewable energy sources. Results from this publication conclude that committed higher percentage of renewable energy portfolio (REP) results in a comparatively higher investment and somewhat lower cost of operation. It also concludes that the policy makers make use of GEP to identify the most efficient and economically feasible policy while also determining the most suitable renewable portfolio standard (RPS) or emission penalties.

Visible and effective leadership and commitment by high level policy and decision makers is important for significant policies regarding the renewables [15]. Policies to stimulate the growth of industries that manufacture, supply and trade RESs with solutions must be introduced. Strong and stable financial services and institutions for private and public investments must be implemented which have high transparency and accountability [15]. Many publications discuss the significance of penalties, FIT, FIP and RPS in policy making and their repercussions Vis a Vis renewable energy systems efficient deployment and acceptance in the current era [16]. Narayanan et al., in [17] discuss and propose the significance and inclusion of micro renewable energy 
systems (MRES) in the future policies to maximize the utilization of renewables. According to [18], strict quota rules are needed for renewable energy development as well as punitive measures are needed for those who do not achieve the production and dispatch targets. Effective communication is needed between the state-grid and renewable energy generators. A detailed literature about latest renewable policies in the US and EU [19] compares and discusses the effective renewable policies which have been formulated and implemented in these regions. The discussion again highlights the significance of smart-grid based energy management, monitoring and storage systems to achieve the goal of efficiency in modern micro and large-scale renewable energy systems. The discussion in [19] describes the significance of renewable energy certificates (RECs) and FiTs which are being widely used in modern renewable policies, particularly in the policies formulated by the key global players in renewable energy systems and their implementations. According to this discussion the RECs ensure maximum possible inclusion of RESs by allocating compulsory or committed generation capacities. It also introduces and states the significance of RPS and solar renewable energy certificates (SRECs). The discussion concludes with remarks that the EU and the US have introduced micro-generation and smart-grid initiatives in their policies. Further, incentives for private sector have been proposed to ensure their participation in the research, manufacturing and deployment domains of RETs. In [20], renewable policies of different countries have been discussed and their salient features have been described and compared. The common targets of these policies include increase in renewable energy, increase in renewable efficiency, energy security and sustainability, competition in renewable energy generation and sustained environmental protection.

In [21], the significance of RPS, Production Tax credits, FiTs and net-metering in renewable policies have been discussed in the USA and its states. The discussion in [22] stresses upon the restructuring of financial models in renewable policies to maximize the investment potential of the interested parties in the market. This would help create a healthy environment favoring the growth and investment in RETs. Enerallt, a market based inter-region energy system model, has been proposed in [23] in an attempt to model a common energy market based on RETs, implementation of which would require a policy shift by the participating countries. Authors of [24] discuss traditional renewable policies at a stretch and identify and propose areas where new policy formulation or improvement is required. These proposed areas for policy formulation and improvement include RPS, Net-metering policy, renewable energy certificate (REC), electricity feed-in law, public benefit funds, investment support, fiscal and financial measures, tenders and quotas, emissions trading policies and renewable energy targets.

Nearly all of the previous works discussed here state many common improvement factors in the renewable policies being formulated and implemented around the globe. These also discuss the existing challenges along with areas having significant room for improvement as far as policy formulation or policy restructuring is concerned. Many new business, financial and technological models have also been proposed which could be used globally to implement an effective and sound policy related to renewables.

\section{Renewable Energy Development and Implementation around the Globe}

Renewable Energy policies vary globally but share the common objective of achieving the deployment and promotion of renewable energy technologies at the least cost and minimum damage to the local and global environment. Elements commonly shared by all these policies include a specific target, an annual target, a set of feasible and eligible renewable technologies (RETs), policies and considerations regarding the import of equipment related to RETs and an effective compliance and enforcement structure. This section discusses modern renewable policies which are evolving with every passing day for feasible and effective adoption and implementation of RETs for self-sustained, secure and environmentally friendly power generation systems.

\subsection{Policies to Integrate ICT Technologies with RETs}

To achieve the goals of efficient power generation, transmission, distribution and end-use, global renewable policy formulation regimes are earnestly looking forward to introducing policies which ensure integration of information and communication technology (ICT) with newly deployed as well as existing grid infrastructure. The prime example of implementation of ICT in the domain of renewable energy systems is in the form of smart grid. Smart grid systems employ various ICT based mechanisms to enhance power quality and stability particularly where intermittent renewable energy sources contribute to the electricity grid. 
Renewable Energy policies vary globally but share the common objective of achieving the deployment and promotion of renewable energy technologies at the least cost and minimum damage to the local and global environment. Elements commonly shared by all these policies include a specific target, an annual target, a set of feasible and eligible renewable technologies (RETs), policies and considerations regarding the import of equipment related to RETs and an effective compliance and enforcement structure. This section discusses modern renewable policies which are evolving with every passing day for feasible and effective adoption and implementation of RETs for self-sustained, secure and environmentally friendly power generation systems.

Smart grid technologies make use of ICT for gathering information related to generation transmission and distribution performances and also for actuating processes that make the overall system resilient with enhanced power quality, sustainability and economy with regard to the power systems.

The evolving smart grid technology brings along with it a novel concept related to demand-side response and management system, known as the Electric Spring, to achieve high standards of power quality and overall distribution system stability with the introduction of intelligent and interactive smart loads to the existing power supply infrastructure [25]. Modern renewables policy making approach must focus on this concept as the smart loads cater for nondeterministic or fluctuating power generation by dynamically varying the load demand, specifically for non-critical loads. Smart loads are in essence power reactive power controllers based on modern power electronics, integrated with non-critical end-use devices or loads. Secondly, such a system is also proposed to be capable of self-regulating the voltage values at the distribution-side where intermittent generation sources are connected. Introduction of such systems as per policy would help mitigate the issue of voltage fluctuation particularly in areas where intermittent RESs are connected to the grid. Smart loads are expected to be capable of dynamically injecting reactive power to the distribution-side network to achieve localized support for voltage adjustment [25].

In order to streamline the integration of renewable technologies to the grid, the use of smart grid technology has increased manifolds. Utilities are increasingly making use of them to ensure optimum performance and uninterruptible delivery. The current urbanization trends demand for increased use of renewable technologies which are now contributing towards the efficient demand and supply management. This increased utilization of renewable energy sources has also introduced risks related to voltage and power fluctuations, harmonics, frequency mismatch and inefficiencies in generation, transmission and distribution. With the introduction of policies and solutions using smart grid technologies, small distributed energy sources can be integrated to an urban power supply network allowing real-time management and optimization of such integrated systems with the existing infrastructure. Such solutions are bound to play an essential role in sustainable development of smart cities along with other ventures aiming at establishment of self-sustaining and self-sufficient energy generation and distribution systems. Figure 1 shows a scalable model for smart grid-based setup with renewable energy sources integrated with the primary grid [26].

Another direction, again based on ICT in general and smart grid in particular is the policy-based introduction of smart city concept amongst the masses and relevant industries. A Smart city comprises of several components which are core to its concept as a future efficient and cost-cutting technology utilizing the best features of smart grid technology. These components include effective governance, mobility of assets and contributing resources, economy and efficient energy harnessing and subsequent power distribution practices. These components could play a key role in achieving a sustainable urban life, integrating power generation, distribution and end-use infrastructure along with various contributing stakeholders. Smart cities are considered to be a logically extended concept of smart grid technology and its practical implementation is of utmost importance to the modernization process of the traditional power systems. Policy formulation related to the introduction of smart grid systems in general and smart city concept in particular must be focused on grid integration of renewable energy resources, agile, stable, efficient and capacious energy storage systems, smart lighting systems and electric vehicles for a green global environment, energy security and sustainability [27].

Policy making is also bound to be focused on the research, development and introduction of new power electronic devices capable of either taking remote commands using communications infrastructure or making intelligent decisions in real-time to manage the power systems for its smooth performance. These devices are being used to integrate distributed generation (DG) or renewable power generation systems at the main supply with energy storage systems (ESSs) working in parallel, particularly in the case of solar and wind-based power generation setups. In conjunction with network infrastructure and smart meters, these devices can be used for 
power grid automation and control. These devices can also play an important role for grid infrastructure security, effective demand response and power quality [28].

Integration of ICT technologies to RETs has been adopted as a core part of new renewable policies around the globe, particularly by the countries of the developed world. The introduction of these policies is still in somewhat early stages yet their introduction has started providing substantial dividends to those countries in the form of secure, stable sustainable, efficient and effectively manageable power infrastructure with an ever-increasing chunk of renewable energy systems contributing to the overall power infrastructure. Introduction of these policies has also started to help achieve green environment with minimal harm to natural and ecological processes. Further research and development as a part of policy will accelerate the adoption rate of this technology with increased sustainable development and better global environment.

\subsection{Policies to introduce new business, financial and planning models for effective adoption of renewable energy systems}

Business models pertaining to any global or regional market play a key role in adoption or promotion of a particular technology. If the business model is sufficiently effective, industries and masses can be compelled to adopt a technology which, according to technologists and policy makers, is good for the community and industry but is not experiencing substantial adoption.

In order to overcome high initial investment costs, environmental constraints impeding the deployment of RET based systems, commercialization difficulties, issues related to deployment, operations and maintenance and the barriers including unstable power supply and low system efficiencies, an integrated system of diverse energy sources, as discussed in the previous sub-section, is needed along with a new business model [5]. These issues cannot be overcome without government support and require a clearly defined business and financial models designed initially formulated and implemented by the government with sufficient incentives and guarantees to lure in investors and stakeholders. Several governments are working in the direction of discovering an optimum business model for their indigenous as well as regional renewables market to accelerate the promotion and adoption of RET based systems. One such model is the ICT model, being introduced in the developed world to create energy efficient power infrastructure fully integrated with multiple RET based power sources. The efficiency offered by such systems itself is an attraction for the investors and other new entrants to the renewables market.

Another renewables expansion model is the generation expansion planning (GEP) model. The purpose of GEP is to identify the most economically viable and optimal combination of traditional and renewable energy sources to accommodate for predicted power demand [14].

Micro Renewable Energy Systems (MRES) deployment model is another dimension which could be opted by policy makers not only to encourage the use of RETs but also to meet the ever-increasing demand of power in a distributed manner. MRES involves RET based power generation units of less than $5 \mathrm{kWh}$ capacity. These systems are either community owned or individually maintained to fulfill the daily requirement of scattered or distributed communities. The main aim of using MRES is to reduce reliance on traditional non-renewable systems which further helps reduce the harmful impact of fossil-fuel based systems with regard to the greenhouse gases (GHGs) [17]. With effective policies in support of MRES model in place, micro renewable energy devices will become popular enough to be readily bought by the people allowing energy independence.

The problems currently being faced by such micro renewable energy systems is the lack of their commercial presence and inefficiency of such systems. These problems can be significantly overcome once the MRES model comes into action as this would also bring along improvements in such systems with broader commercial presence. Governments and their policy making bodies must direct funding towards R\&D of such systems with subsidies, incentives and guarantees to ensure affordability and deeper penetration of such systems to the mainstream renewables market. Table 1 shows the advantages that come along the implementation of MRES model [17].

As far as investment and financial models are concerned, they face a few constraints in the form of lack of innovation in the RET systems deployment methodologies and investment climate. The innovation model itself involves economic risks, political climate dependence, natural risks, social acceptance, governance issues and natural factors determining its effectiveness. Innovative models and projects depend upon initial costs, time required for market maturity and time required to bring the innovation to the market. Innovation is 


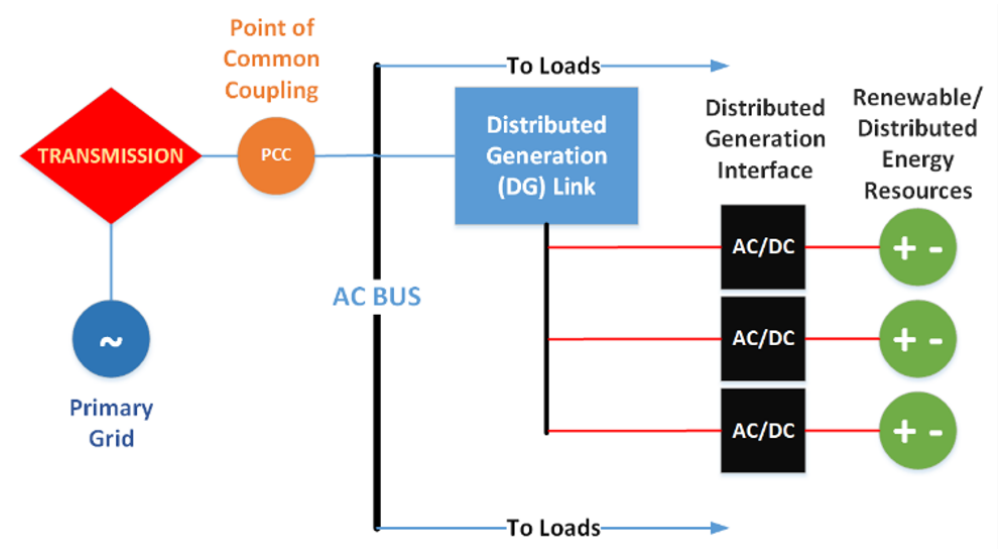

Figure 1. Model for smart grid with renewable energy sources and primary grid integration

strictly involved in the maturity and stability of the investment and financial models. Next to the innovation model, there are two further finance models which require policy-makers attention. These include (i) program-targeted financing model and (ii) market-based financing model. These two models differ on the basis of their objectives and financing structures and sources.

In the case of program-targeted financing model of RES development, government gets directly involved in funding implementing non-debt-based funding structure. This model may also include the involvement of government-owned enterprises in partnership with private investors. The funding in this scenario is more targeted towards domestic socio-economic progress and self-sufficiency in RET based power generation. In the market-based financing model, general market mechanics work as the core driving factors like demand and supply trends, profit earning and sharing mechanisms and risk reduction practices. Unlike the program-targeted financing model, this model focuses on export of energy on region-wide scale. The program-targeted model may prove beneficial for the developing or cash-starved nations while the market-based financing model is likely to work better with developed nations. Both these models can prove beneficial for the development of alternative energy sources and should be the focus of renewable energy policy makers. These models would help enhance the energy potential of industries, create suitable environment for increased investments in the renewables domain and would help create more competitive market base. Having these models implemented would most likely ensure self-sufficiency, energy security and socio-economic well-being.

Table 1. Advantages of MRES model

\begin{tabular}{l|l} 
Advantage & Impact \\
\hline Self-sufficiency in Power generation & $\begin{array}{l}\text { Savings on utility bills and additional source of } \\
\text { income }\end{array}$ \\
\hline $\begin{array}{l}\text { Community/individual ownership and } \\
\text { participation in RET based systems deployment }\end{array}$ & $\begin{array}{l}\text { Higher approval of RET based systems adoption } \\
\text { and job creation }\end{array}$ \\
\hline Localized power generation & Energy security and reduced cost of logistics \\
\hline $\begin{array}{l}\text { A new technological domain with improvised } \\
\text { generation methods }\end{array}$ & $\begin{array}{l}\text { An impetus to technological advancement and } \\
\text { newer sources of income }\end{array}$ \\
\hline $\begin{array}{l}\text { Independence from energy market fluctuations and } \\
\text { volatility }\end{array}$ & Reduced bills with higher system stability
\end{tabular}

\subsection{Policy recommendations to ensure deep penetration of RET based systems}

Policy making with regard to renewable energy systems has witnessed significant growth and maturity over the past decade. Many countries have evolved different policy models to ensure the penetration of renewable energy systems to the national and regional markets. A similar role is being played by the global renewable policy making regimes to permeate the policy effects across the globe so that the growth of RET based systems is uniformly experienced by the global stakeholders. There are several recommendations 
which are either in place or are being considered by different countries for the promotion of renewable energy systems. Some of the policy recommendations are in nascent stages and need to be earnestly looked at by the policy makers to achieve the desired objectives.

\subsubsection{National Energy Action Plan:}

Such action plans need to be adopted to ensure formulation and implementation of a stable renewables policy so that the significance of RET could be realized at national level. This would also help reshape industries in accordance with renewable policies and would help renewables market to evolve in the mainstream.

\subsubsection{Production Tax Credits (PTCs):}

Production Tax Credits must be offered to the manufacturers of RES related devices. Demand Response (DR) management providers should also be offered such credits. These credits work as an incentive for the promotion of renewable systems and gradually discourages the use of traditional fossil-fuel based generation systems. PTCs will attract private investment and will minimize the investment risks often faced during the implementation of newly evolving technologies.

\subsubsection{Reduction or removal of subsidies:}

Subsidies which are being offered to the power producers using traditional fossil-fuel based technologies should either be gradually reduced or be removed altogether. This move would definitely help masses and industries alike in opting for renewable generation systems to fulfil their energy requirements while conserving the natural environment and climate.

\subsubsection{Policies related to Feed-in Tariff (FIT):}

A balanced and attractive feed-in tariff policy must be formulated, based on the type of renewable energy technology used, to encourage the independent or individual renewable energy suppliers so that the contributors get rewarded for the amount of power they are injecting into the power supply system. The FIT's mechanism is such that the government agencies mandate the distribution companies to purchase power generated by RE based generators at a fixed or pre-decided price over an extended period. This allows RE based power companies to make investments which are less risk-prone by allowing them to have a known fixed retail price of electricity. This property of FIT mechanism has allowed it to be more popular way of contributing with the RE based power [9]. FIT is often regarded as an incentive which has been implemented by many countries across the globe. FIT and its related policies encourage small businesses to deploy and maintain RE sources. The main factors that these tariffs include guaranteed and committed grid access, power trade at market-based price, long-term power purchase agreements, [19].

\subsubsection{Policy related to Renewable Policy Standard (RPS):}

The RPS ensures that the power being contributed to the electricity supply system using RET costs more than the standard wholesale price of the electricity. It not only rewards the suppliers with the amount of power they are injecting but also helps them get their due share for the maintenance and up keeping of the renewable energy harnessing assets they have deployed [9]. The RPS comprises of the following key elements: (i) setting the mandatory quota of power generated using RES as stipulated by the government agencies; (ii) issuance of Tradable Green Certificates (TGCs) to RES based power suppliers based on their respective contribution; (iii) selling and purchasing of predefined quota certificates between stipulated targets and RE based suppliers. Setting of such mandatory targets helps adopt RE based set-ups at low cost resulting in high adoption trend of such systems. The main difference between the FiT and RPS is that the FiT is purchase price oriented while RPS is installed capacity oriented. In general, price regulations apply on FiT and quantitative regulations apply on RPS [16]. If FiT and RPS are compared for their effectiveness, the former has been found to be more productive in proliferating the RET based systems owing to its popularity and capability to help inject more RE based power into the system. Despite the popularity of FIT based systems, RPS system can be further improved to help the growth of RE based systems deployment. One drawback found with the FIT is that it causes the price of deployment and devices to increase manifolds. RPS based system, if implemented with a 
few improvements, may help create a balance between the adoption of all types of RET based systems keeping device and deployment costs in check [16]. RPS is basically designed to maintain a mix of different RESs hence giving the opportunity to less-adopted Renewable technologies to evolve further [19].

\subsubsection{Ecotax:}

Ecotax system as a part of policy allows policy makers and concerned government agencies to give tax incentives to entities that build or are interested in deploying RE based sources. Such a system is most effective when those individuals, utilities or power distributors are penalized which contribute to pollution and harm to the environment [19].

\subsubsection{Renewable Energy Credits (RECs):}

Renewable energy credits ensure maximum adoption of RE based systems by assigning mandatory generation capacities. RECs can be traded between companies to guarantee generation using RET based systems [19].

\subsection{Formulation of effective renewable energy laws}

Energy laws play an important role to promote the development and adoption of RESs. Energy laws are designed to enhance the energy efficiency and help conserve the energy by introducing different legal regulatory measures. Laws, particularly with regard to renewable energy systems, help formulate economic incentives and energy control in an effective and flexible manner [8]. In order to develop and promote RES, consistent policies are needed. For RES to flourish on a national level, it is important that the investors, developers, researchers and end-users find it viable to make decisions on long-term basis as far as adoption of RETs is concerned [8]. The renewable energy law comprises of a policy framework which help establish key policy ingredients like national RE targets, compulsory connection and purchase policy, a FIT system according to national priority, strategies for funding and financing of RE incentives. The primary objective of such laws is to save energy and protect the deteriorating environment [18]. Introduction of new and improved energy laws have been found to be capable of expediting the development and implementation RETs at a large scale.

The key mechanisms that contribute to the effective renewable energy law are as follows;

1. Clear and elaborate definition of renewable energy or green energy sources. The national target should be prioritized utilization of these sources to meet energy demands.

2. Governmental agencies looking after energy affairs must be made responsible for planning and management of renewable energy. If need be, dedicated agencies must be formed that work in conjunction with the existing agencies.

3. Transmission and dispatch companies should sign agreements with RE based generators to purchase the generated power and provide related services for the ease of their functioning.

4. A targeted percentage of RE must be stipulated in the newly formulated laws to ensure that a mandatory chunk of energy comes from RE sources.

5. The central government must be capable of looking after the law implementation and must intervene wherever policy related loopholes or legal misconduct is found.

6. Special funding regimes must be formed, the sole purpose of which should be to support the research and development of efficient and cost-effective RETs [18].

\section{Global Renewable Policy Implementation and Comparison}

This section of the paper reviews policies and energy strategies of a few countries, most of which are global leaders in successful development and implementation of RETs. It also encompasses policy-based measures being formulated for environmental protection and proliferation of RE based systems.

The world has been witnessing a steep rise in energy demand to achieve the goals of development not just at industrial scale but also at the level of masses. People around the globe have started realizing the importance of renewable energy technologies and energy conservation as these contribute not just towards environmental protection but also towards the creation of new avenues and dimensions of economics. Of all the RE sources and technologies available, the most sought-after technologies and sources have been solar, wind and hydropower. With evolving policies Vis a Vis RE sources, the world has experienced sharp increase 
in the use of almost all forms of RE sources as it has been realized that the use of RETs is necessary to achieve self-reliance, energy security and environmental protection. Renewable energy policies of many countries have contributed to growth in the market volume of RE systems and also to the increase global trend of adoption for such systems. In the pursuit of efficient RE system, policies of many countries have helped evolve new technologies which complement the use of RE to a great extent. These new technologies or approaches include hydrogen fuel-cell based storage systems, ICT and nano-technology based power management and control systems. Even though many countries have effective policies in place regarding RES, there still remains enough room for improvement of such policies to make them more effective.

\subsection{Renewable Energy Policies of Australia}

The Australian government, in several of its energy policy frameworks, has set targets of achieving secure, reliable, green and low-cost energy to domestic and industrial consumers in Australia. Another objective that was clearly defined was the attainability of sustainable development of national energy sources. The government also decided to create and maintain a regulated and competitive energy market for the propagation of energy harnessing using cost-effective, efficient and clean technologies. Energy efficiency and security being the primary objectives of the Australian government and policy makers, the country has established several new RE based generation systems with large energy storage projects, the most popular being the 129 MWh Hornsdale Power Reserve Complex in Southern Australia, complementing the working of 315 MW Hornsdale windfarm project.

\subsection{Renewable Energy Policies of Brazil}

The Brazilian government is mainly targeting energy efficiency and market liberalization with regard to $\mathrm{RE}$ systems. The focus for establishment of RE systems is not just to entertain the residential consumers but also the Industrial consumers. Brazil being one of the major producers of clean and green RE in the world owing to the presence of several hydel sources, is focusing on biofuel-based projects owing to the presence of Amazon Rain Forest on its mainland which is capable of delivering huge amounts of biomass for that purpose.

\subsection{Renewable Energy Policies of China}

Owing to effective new policies regarding renewable energy, China is undoubtedly the single largest renewable energy producer. China is taking the issue of climate change seriously and has put in place several policies regarding conservation of ecology and environment for sustainable development and better socio-economic future of the country. The National Development and Reform Commission of China, in 2012, introduced the pilot carbon cap and trade scheme to minimize the carbon emission to the environment for a cleaner and greener future. These effective policies have made China the leading user of PV, hydro and wind based RE systems [20].

\subsection{Renewable Energy Policies of EU}

EU has set several new targets through legislation to achieve energy security and climate conservation using renewable energy. They EU's policy makers have put forth several proposals to ensure the availability of a green energy harnessing environment through several policy proposals, in particular the 20/20.20, like;

1. $20 \%$ Reduction in the emission of greenhouses gases (GHGs),

2. $20 \%$ increase in the overall energy efficiency,

3. Increase the contribution of renewable energy by $20 \%$,

4. Increase the contribution of biofuels for transport by $10 \%$.

$\mathrm{EU}$, as a single contributor to the renewable energy domain, is one of the leading RE producers. Effective policies of the EU have allowed common individuals and small industries to contribute renewable energy, often in surplus [20].

\subsection{Renewable Energy Policies of India}

India's energy needs are driven by its huge population living without access to electricity. With huge burden on other energy sources, the need has driven the Indian government to formulate highly effective 
renewable energy policy to make energy available for all, regardless of geographical location. India has now become one of the leading users of biofuels, wind and solar power due to highly focused policy making of the Indian government. One such policy is India's Integrated Energy Policy (IEP) which has helped meeting energy demands, ensured secure energy supply, protection of the environment and deeper penetration of RET based systems [20].

\subsection{Renewable Energy Policies of Japan}

Japan's renewable policy revolution came after the post-tsunami Fukushima Nuclear Power Complex incident in the year 2011. The Japanese government is now earnestly looking forward to establishing as many renewable avenues as possible to mitigate the use of renewable and fossil-fuel based energy systems to ensure energy security and environmental protection. Japan has also become one of the leading contributors to the research and development and integration of ICT with the existing and renewable based grids. Currently, most of the focus is in the direction of hydro based projects and also Boron and Hydrogen fuel cells-based systems [20].

\subsection{Renewable Energy Policies of the USA}

Despite being one of the largest contributors to RETs, the US still does not have an effective policy regarding renewable energy systems, mainly due to impediments in policy making and capitalist mindset. Currently, both renewable and non-renewable energy systems have been offered similar tax and deployment incentives which has not allowed blooming of renewables to a great extent [20].

\section{Conclusion}

Renewable Energy has become an unavoidable need for the sustainable future. These systems are important not only for energy security and self-sufficiency but also for the preservation of the global natural environment. In order to ensure deeper and timely penetration of RES as an essential source of energy at a global scale, there is an urgent need to make global and regional policy-makers realize that there is a need to make effective policies to promote the use of RESs in an economical and attractive way. An efficient, stable and reliable energy distribution system calls for increased use of ICT based management, control and storage systems. Policies to mitigate the use of traditional fossil-fuels as a source of energy should also be formulated on priority by imposing penalties on the power-producers heavily relying on fossil-fuels. Policies to promote R\&D for more reliable and efficient RESs must be formulated as it would guarantee a long-lasting, clean and stable energy source. The policy makers and relevant regulating authorities must be made independent and fully responsible for achieving RE growth targets. This target-oriented approach would help them work with dedication and independence to achieve the stipulated goals of achieving massive growth in RES based generation capacity and self-sufficiency. Such pro-active and effective policy making bodies could make a big difference regarding the spread and adoption of RES locally and globally.

Author Contributions: All authors contributed equally to the writing of this paper. All authors read and approved the final manuscript.

Conflicts of Interest: "The authors declare no conflict of interest."

\section{References}

[1] Farah, P. D., \& Rossi, P. (2011). National energy policies and energy security in the context of climate change and global environmental risks: A theoretical framework for reconciling domestic and international law through a multiscal. European Energy and Environmental Law Review, 20(6), 232-244.

[2] Hamilton, M. S. (2014). Energy Policy Analysis: A Conceptual Framework: A Conceptual Framework. Routledge.

[3] Foni, S., Pecorella, T., Fantacci, R., Carlini, C., Obino, P., \& Di Benedetto, M. G. (2017, September). Evaluation methodologies for the NB-IOT system: Issues and ongoing efforts. In 2017 AEIT International Annual Conference (pp. 1-6). IEEE.

[4] Shokri, A., \& Heo, E. (2012, February). Energy Policies to promote Renewable Energy Technologies; Learning from Asian Countries Experiences. In Conference: International Association for Energy Economics (pp. 1-10).

[5] Han, S., \& Shin, H. W. (2014, October). Policy trends of renewable energy in Korea. In 2014 International Conference on Renewable Energy Research and Application (ICRERA) (pp. 218-221). IEEE. 
[6] Mondal, M. A. H., Bryan, E., Ringler, C., \& Rosegrant, M. (2016, January). 100\% electrification and renewable based Ethiopian power sector development strategies. In 2016 th International Conference on the Development in the in Renewable Energy Technology (ICDRET) (pp. 1-4). IEEE.

[7] Fagiani, R., \& Hakvoort, R. (2014, May). Simulating the performance of market-based policies for renewable energy using learning trading agents. In 11th International Conference on the European Energy Market (EEM14) (pp. 1-5). IEEE.

[8] Yun-wei, S. (2010, November). American policy on renewable energy and its inspiration. In 2010 International Conference on Management Science \& Engineering 17th Annual Conference Proceedings (pp. 1513-1519). IEEE.

[9] Murthy, N., \& Bojanczyk, K. (2013, July). Linkages in energy policy and technology: grid-scale renewables integration at high penetration levels requires sustained and corrective policy support. In 2013 IEEE Power E Energy Society General Meeting (pp. 1-5). IEEE.

[10] Ogunrinde, O., Shittu, E., \& Dhanda, K. K. (2018). Investing in renewable energy: Reconciling regional policy with renewable energy growth. IEEE Engineering Management Review, 46(4), 103-111.

[11] Ksenia, C., Riffat, S., \& Jie, Z. (2010, January). An overview of renewable energy policies and regulations in People's Republic of China. In 5th International Conference on Responsive Manufacturing-Green Manufacturing (ICRM 2010) (pp. 420-424). IET.

[12] Yunchang, S., Zhaozheng, S., Yiyun, W., Lei, C., Chunming, X., \& Qingzhe, J. (2011, May). Development situation and policy suggestions of Chinese renewable energy. In 2011 International Conference on Materials for Renewable Energy $\mathcal{E}$ Environment (Vol. 1, pp. 1-4). IEEE.

[13] Shyam, B., \& Kanakasabapathy, P. (2017, December). Renewable energy utilization in India-policies, opportunities and challenges. In 2017 International Conference on Technological Advancements in Power and Energy (TAP Energy) (pp. 1-6). IEEE.

[14] Dang, C., Wang, X., Xiao, Y., Du, C., \& Zhang, W. (2014, October). An improved generation planning method incorporating renewable energy policy. In 2014 International Conference on Power System Technology (pp. 759-766). IEEE.

[15] Waikar, D. (2010, February). Policies and practices for renewable energy: An international perspective. In 2010 The 2nd International Conference on Computer and Automation Engineering (ICCAE) (Vol. 5, pp. 182-184). IEEE.

[16] Zheng, H. T., Watts-Jones, S. R., \& Ravesteijn, W. (2014, August). The implementation of Renewable Energy policies-Wind energy electricity in Xinjiang autonomous region. In 2014 International Conference on Management Science E Engineering 21th Annual Conference Proceedings (pp. 1636-1644). IEEE.

[17] Komerath, N., Venkat, V., Halka, M., \& Soloway, D. (2009, October). Micro renewable energy systems: Synergizing technology, economics and policy. In 2009 Atlanta Conference on Science and Innovation Policy (pp. 1-8). IEEE.

[18] Zheng, H. T., Watts-Jones, S. R., \& Ravesteijn, W. (2014, August). The implementation of Renewable Energy policies-Wind energy electricity in Xinjiang autonomous region. In 2014 International Conference on Management Science E Engineering 21th Annual Conference Proceedings (pp. 1636-1644). IEEE.

[19] Izadian, A., Girrens, N., \& Khayyer, P. (2013). Renewable energy policies: A brief review of the latest US and EU policies. IEEE Industrial Electronics Magazine, 7(3), 21-34.

[20] Aktas, A. Z. (2015, November). A Review and comparison of renewable energy strategies or policies of some countries. In 2015 International Conference on Renewable Energy Research and Applications (ICRERA) (pp. 636-643). IEEE.

[21] Singarao, V. Y., \& Singh, R. P. (2014, April). Review of state and national renewable energy policies. In 2014 Sixth Annual IEEE Green Technologies Conference (pp. 81-86). IEEE.

[22] Kulikova, N. N. (2016, June). Features of financing innovative renewable energy development. In 2016 11th International Forum on Strategic Technology (IFOST) (pp. 315-318). IEEE.

[23] Zakeri, B., \& Syri, S. (2016, June). Intersection of national renewable energy policies in countries with a common power market. In 2016 13th International Conference on the European Energy Market (EEM) (pp. 1-5). IEEE.

[24] Singh, R., \& Sood, Y. R. (2008, April). Policies for promotion of renewable energy sources for restructured power sector. In 2008 third international conference on electric utility deregulation and restructuring and power technologies (pp. 1-5). IEEE.

[25] Kanjiya, P., \& Khadkikar, V. (2013, October). Enhancing power quality and stability of future smart grid with intermittent renewable energy sources using electric springs. In 2013 International Conference on Renewable Energy Research and Applications (ICRERA) (pp. 918-922). IEEE.

[26] Shahid, A. (2018, October). Smart grid integration of renewable energy systems. In 2018 7th International Conference on Renewable Energy Research and Applications (ICRERA) (pp. 944-948). IEEE.

[27] Atasoy, T., Akinc, H. E., \& Ericn, Ö. (2015, November). An analysis on smart grid applications and grid integration of renewable energy systems in smart cities. In 2015 International Conference on Renewable Energy Research and Applications (ICRERA) (pp. 547-550). IEEE. 
[28] Martins, P. E. T., Oleskovicz, M., \& da Silva Pessoa, A. L. (2019, September). A Survey on Smart Grids: concerns, advances, and trends. In 2019 IEEE PES Innovative Smart Grid Technologies Conference-Latin America (ISGT Latin America) (pp. 1-6). IEEE.

[29] Sijm, J. (2005). The interaction between the EU emissions trading scheme and national energy policies. Climate Policy, $5(1), 79-96$.

[30] Aized, T., Shahid, M., Bhatti, A. A., Saleem, M., \& Anandarajah, G. (2018). Energy security and renewable energy policy analysis of Pakistan. Renewable and Sustainable Energy Reviews, 84, 155-169.

[31] FortuÅĎski, B. (2020). Sustainable development and energy policy: Actual CO2 emissions in the european union in the years 1997-2017, considering trade with china and the USA. Sustainability, 12(8), 3363.

[32] Afgan, N. H., \& Carvalho, M. G. (2004). Sustainability assessment of hydrogen energy systems. International Journal of Hydrogen Energy, 29(13), 1327-1342.

[33] Singhal, D., \& Swarup, K. S. (2011). Electricity price forecasting using artificial neural networks. International Journal of Electrical Power \& Energy Systems, 33(3), 550-555.

[34] Li, L., Liu, J., Zhu, L., \& Zhang, X. B. (2020). How to design a dynamic feed-in tariffs mechanism for renewables: A real options approach. International Journal of Production Research, 58(14), 4352-4366.

[35] Clarke, L., Edmonds, J., Krey, V., Richels, R., Rose, S., \& Tavoni, M. (2009). International climate policy architectures: Overview of the EMF 22 International Scenarios. Energy Economics, 31, S64-S81.

[36] Apergis, N., \& Payne, J. E. (2010). Renewable energy consumption and economic growth: evidence from a panel of OECD countries. Energy Policy, 38(1), 656-660.

[37] Lipp, J. (2007). Lessons for effective renewable electricity policy from Denmark, Germany and the United Kingdom. Energy Policy, 35(11), 5481-5495.

[38] Menanteau, P., Finon, D., \& Lamy, M. L. (2003). Prices versus quantities: choosing policies for promoting the development of renewable energy. Energy Policy, 31(8), 799-812.

[39] Mainardis, M., Buttazzoni, M., \& Goi, D. (2020). Up-flow anaerobic sludge blanket (UASB) technology for energy recovery: a review on state-of-the-art and recent technological advances. Bioengineering, 7(2), 43.

[40] Dusonchet, L., \& Telaretti, E. (2015). Comparative economic analysis of support policies for solar PV in the most representative EU countries. Renewable and Sustainable Energy Reviews, 42, 986-998.

[41] Evans, A., Strezov, V., \& Evans, T. J. (2012). Assessment of utility energy storage options for increased renewable energy penetration. Renewable and Sustainable Energy Reviews, 16(6), 4141-4147.

[42] Eitan, A., Herman, L., Fischhendler, I., \& Rosen, G. (2019). Community-private sector partnerships in renewable energy. Renewable and Sustainable Energy Reviews, 105, 95-104.

[43] Burke, M. J., \& Stephens, J. C. (2018). Political power and renewable energy futures: A critical review. Energy Research $\mathcal{E}$ Social Science, 35, 78-93.

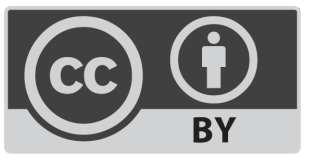

(C) 2021 by the authors; licensee PSRP, Lahore, Pakistan. This article is an open access article distributed under the terms and conditions of the Creative Commons Attribution (CC-BY) license (http://creativecommons.org/licenses/by/4.0/). 